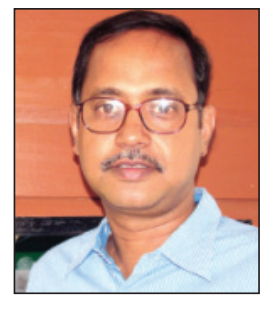

INDIAN JOURNAL OF POWER \& RIVER VALLEY DEVELOPMENT www.ijprvd.info ff

INNOPOWER $\boldsymbol{R}^{\mathrm{TM}}$

Jayanta Bhattacharya

\title{
Energy-saving innovation for magnesite transport bed flash calcinations (TBFC) process
}

Magnesite is a mineral with the chemical formula $\mathrm{MgCO}_{3}$. Iron, manganese, cobalt and nickel may occur as admixtures, but only in small amounts. Magnesite has a chemical composition of $\mathrm{MgCO}_{3}$, and when it is heated it will dissociate into $\mathrm{MgO}$ and $\mathrm{CO}_{2} . \mathrm{MgO}$ has an extremely high melting temperature, and that makes it a good refractory material in many steelmaking, metallurgical, and ceramic processes. $\mathrm{MgO}$ is one of the most commonly used materials for making the bricks used to line kilns, industrial ovens, and blast furnaces. $\mathrm{MgO}$ is also used to

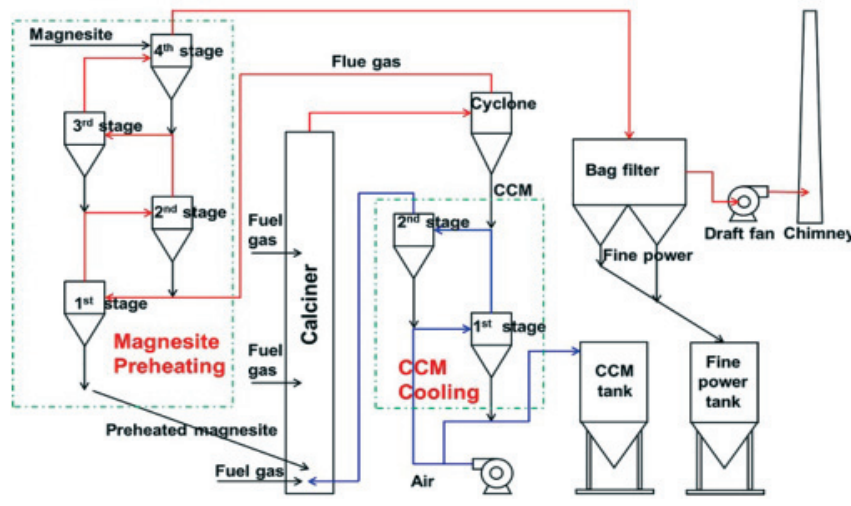

Featured by staged combustion of fuel gas, TBFC process with 2-stage cooling and 4-stage preheating

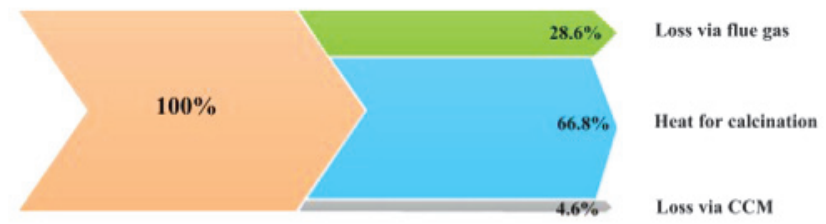

Energy efficiency of TBFC is $66.8 \%$, almost doubly higher than $33.9 \%$ of traditional RF
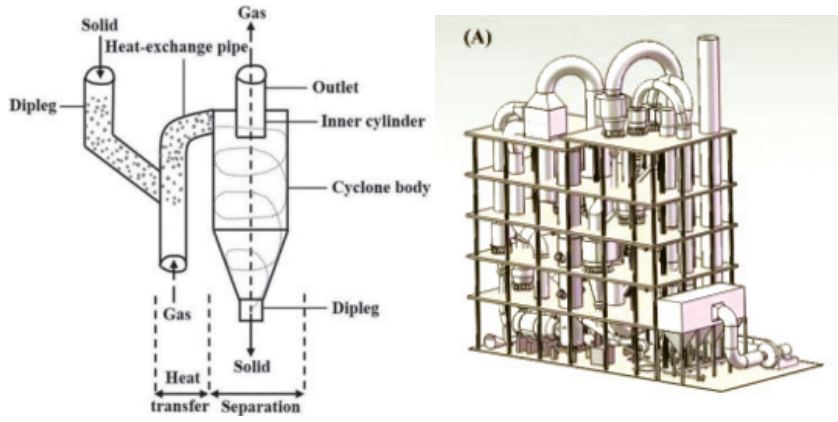

make fertilizers, magnesium chemicals, and refined into magnesium metal. In the magnesite-based industry, light calcination of magnesite is the first step, which occurs at about $1000^{\circ} \mathrm{C}$ to obtain the caustic calcined magnesia (CCM, mainly composed of $\mathrm{MgO}$ ). Here, the term "light" means at relatively low temperatures. CCM is the feedstock for the production of downstream high-value products, such as silicon-steel magnesium oxide, magnesium hydroxide and magnesium cement. In the TBFC magnesite preheating and CCM cooling are respectively 4 and 2 stages, leading to the energy consumption of $4100 \mathrm{~kJ} / \mathrm{kg}-\mathrm{CCM}$ and the energy efficiency of $66.8 \%$, which is almost doubly higher than the $33.9 \%$ of the conventional reverberatory furnaces (RF). The TBFC process is mainly composed of a calciner implementing the light calcination of magnesite, a magnesite preheating system and a CCM cooling system. In the preheating system, the fed magnesite is heated by flue gas from the high-temperature calciner. While, in the cooling system, the high-temperature CCM is cooled down by air sent to the calciner. Herein, a schematic of the TBFC process with two-stage cooling and four-stage preheating is given as an example and shown in the Figure. While TBFC is an innovation over RF, in a new development TBFC is attached with a cyclone-type preheater to preheat the fed magnesite where the particles and gas first proceed heat transfer in the heat-exchange pipe and then they are separated in the cyclone.

For TBFC, the preferred process arrangement is proved to be four-stage preheating for magnesite and two-stage cooling for CCM, and the corresponding energy consumption is about $4100 \mathrm{~kJ} / \mathrm{kg}-\mathrm{CCM}$ and energy efficiency is $66.8 \%$.

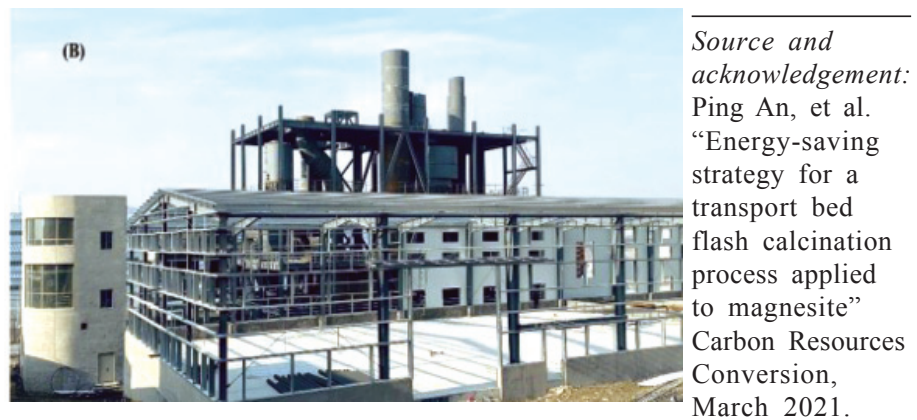

Fig.: A schematic drawing of the cyclone preheater and the TBFC plant under construction 